\title{
Mausoleums in Morocco between Spirituality and Sorcery: Case Study
}

\author{
Soumaya Tifnouti \\ Department of English Studies, Cadi Ayyad University, Marrakesh, Morocco \\ Email: soumayatifnouti@gmail.com
}

How to cite this paper: Tifnouti, S. (2021) Mausoleums in Morocco between Spirituality and Sorcery: Case Study. Open Access Library Journal, 8: e7750.

https://doi.org/10.4236/oalib.1107750

Received: July 12, 2021

Accepted: August 7, 2021

Published: August 10, 2021

Copyright ( $) 2021$ by author(s) and Open Access Library Inc.

This work is licensed under the Creative Commons Attribution International License (CC BY 4.0).

http://creativecommons.org/licenses/by/4.0/ (c) (i) Open Access

\begin{abstract}
This paper deals with controversial issues related to mausoleums in Morocco. The research aims to achieve clarifications concerning the analyzed matter. The reasons for visiting mausoleums are complex and tough to understand. However, spirituality and sorcery are the main reasons for visiting mausoleums. It is difficult to conceal the accuracy of this issue because of the perplexity of the question. The study examines the various reasons concerning people visiting mausoleums and the different wicked and sometimes dangerous practices of the studied communities. The case study investigates the mausoleum "Moulay Abdellah Ben Hussain" in Tamesloht village in Morocco.
\end{abstract}

\section{Subject Areas \\ Culture, Humanities}

\section{Keywords}

Mausoleums, Morocco, Spirituality, Witchcraft/Sorcery, Mysterious Practices

\section{Introduction}

Mausoleums are deeply rooted in the history and culture of Moroccan society. They are known as symbols of Moroccan culture and a source of pride for many Moroccans. The government allocates considerable financial funds that aim to preserve and restore these mausoleums. Practically all the cities or villages in Morocco have their private mausoleum, and usually, their presence is related to the history of this region. Many Moroccans believe that the individual buried in these graves is a saint and will realize their dreams. The issue of visiting sepulchers in Morocco is mysterious. The reasons behind frequenting these mau- 
soleums differ from one person to another. This topic is challenging to study in Moroccan society. The diversity of data is confusing as the sensitivity of this topic needs accurate analysis. Mausoleums are spiritual, social, financial, and therapeutic spots for Moroccans.

\section{Methodology and Hypothesis}

This research emerged from our curiosity and the intellectual quest to investigate this phenomenon. Consequently, we have several hypotheses in the study of this question. Why do Moroccans attend these mausoleums? What are the reasons behind the extravagant enthusiasm of Moroccans visiting mausoleums regularly? From a spiritual perspective, what is the position of Islam, the official religion in this country, about building mausoleums and attending them? One of the biggest problems of this research is that there is practically no bibliography on this topic. We conducted fieldwork in a famous mausoleum named, "Moulay Abdellah Ben Hussain" in Tamesloht not far from Marrakesh city. Our case study is complex as it deals with a delicate topic and people are perplexed to be accurate in their answers. The methodology adopted in this study involves hypotheses, questions, data collection, and the analysis and interpretation of the findings.

\section{Motives of Visiting Mausoleums in Morocco}

The purpose of Moroccans to attend mausoleums is diverse and contradictory. There are numerous mausoleums in Morocco, and people's aims vary depending on the individual buried and his "supernatural powers." Moroccans generally believe that each particular mausoleum possesses its specific blessings and benefits.

The majority of the Moroccans who believe in the superpowers of these so-called saints are people of varying ages, social classes, and educational levels yet bearing the same purposes and beliefs. These people are both males and females, full of despair and distress and visiting mausoleums is a therapy for them. Attending those vaults made them gleam with hope, and optimism persuaded that the blessings and superpowers of the saints will improve their current status. The mausoleums attract thousands of people who think they will be bestowed by the saints and will be granted their wishes. Currently, the mainstream visitors of these mausoleums are women who claim the assistance of these deceased individuals. Most of the mausoleums became famous for the sorcery that invaded the sepulchers' outskirts and not for the claimed blessings nor the noble reputation of the individuals buried inside the graves [1].

Furthermore, those deceased people buried in the mausoleums are supposed to be well-known for their ability to neutralize witchcraft and spell. Consequently, these tombs are attended by all genders, men, and women, adults, and teenagers, educated and uneducated, coming from all areas of Morocco, and suffering from the identical dilemma which is superstition, witchcraft, and black 
magic. Tons of people are gathered around the walls of the mausoleum and inside of it waiting for salvation, and the hope that the claimed blessings of the saint will emancipate them from their hardships and get them back to their life.

Broadly speaking, Moroccans attend mausoleums to heal mental or physical diseases and get married. Marriage is a crucial issue in Moroccan society and culture. Two sorts of Moroccans visit those graves with totally different purposes. The first category is called the good one, and the second is called the evil category. The classified, good category prays for mercy, forgiveness and asks the saint for heaven. This category attends any sepulcher and does not necessarily attend a particular one with specific gifts. It believes that all the saints are loyal servants of God; hence they will intervene for them with God and grant them eternal life in heaven. Concerning the classified evil category, its goals are witchcraft, sorcery, and magic. The deceptive nature of this class has driven to the perversion of the mausoleums' status. The labeled evil kind is a wicked category practicing sorcery and spells to harm others and this is called the satanic cult. Besides, the preponderance of those reckoned saints, the mausoleums become a place for sorcery, satanic activities, and prostitution [1]. Therefore, Moroccans hit mausoleums with different aims to get wellness, wealth, religious, personal, and evil purposes. Numerous reasons drive those Moroccans to attend mausoleums, following their parents and predecessors' customs, coincidence, poverty, discovery, and entertainment besides sorcery. Ultimately, those callers practice numerous rituals depending on the visited sepulcher and the requested desire. This mausoleum is a quiet and peaceful area except for Friday's weekly market, where visitors came to attend and shop in the mausoleum's warehouse [2].

\subsection{Traditions}

There are multiple reasons and factors leading people to visit sepulchers, and tradition is one of them. People tend to follow their inherited culture, beliefs, and traditions blindly. Visiting sepulchers became a habit and a practice passed on from one generation to another. Moroccans tend to transmit this tradition believing in the benefits of it and the help it secures for them. People think that visiting a saint is better than receiving a psycho-therapy. This is how this tradition becomes a commitment and a piece of the Moroccan identity. Not believing in this ancestral custom is considered a betrayal to the family and the nation's culture and beliefs.

\subsection{Poverty}

Poverty plays a predominant role in the embedded beliefs of those people attending mausoleums. Despite the absence of logic, those people believe that dead bodies can help them solve their problems and heal their physical and mental health. Poverty is essentially the main reason for the spread of the superpowers of deceased individuals in Morocco. The majority of Moroccans are ready to believe in anything to help them cope with the hardships of deprivation and po- 
verty. Usually, these people are illiterate, ignorant, and unaware of the dangers of the spread of these beliefs within the community.

\subsection{Entertainment and Culture}

Several famous mausoleums in Morocco organize a festival annually, and visitors come from all over the country to attend these celebrations. The time differs from one sepulcher to another, and it lasts between 3 to 7 days. Visitors enjoy and entertain themselves in the various shows. Those shows are spectacular with horsemen, music and dancing shows, storytellers, and games for kids. In addition, they can discover the history of the monuments, their architecture, and the records of the buried bodies.

\subsection{Enchantment and Wickedness}

Magic and sorcery become popular in the mausoleums in Morocco. Some of these witches pretend to have the ability to heal people from the spells and the harmful "eye", and people rarely discover that they are impostors and sell illusions. Those witches are dangerous and practice their satanic rituals inside the sepulchers considered in the beginning of its existence to be sacred.

\section{The Rituals of the Mausoleums}

Moroccans practice various rituals depending on their gender and the sepulcher they visit. The visitors follow the same rites in all the mausoleums. They start by burning candles and give the blossom's water to the director of the mausoleum, usually a grandchild of the so-called saint, then, give charity to the beggars. Afterward, they head to the tomb to kiss its four corners, and put some money in the cash box, and, eventually, sit next to the tomb for long hours. They start to talk about their problems to the deceased celebrity imploring him to help them. Many times, they start crying and weeping next to the saint to get his sympathy and compassion to grant them their wishes and heal their mental and physical wounds.

Additionally, the so-called saints are known for their fake ability to cure psychological disorders like Bouya Omar's a mausoleum that witnesses weird rituals considered cruel, mean, and dangerous. The victims, in this particular mausoleum, are enchained sometimes for years and beaten brutally as the witches make them believe that they are possessed by demons and that this is the only effective therapy for this kind of disease. Furthermore, mausoleums include some practices as offering blood sacrifices by slaying sheep, cows, camels, and chickens in honor of the saint, and to show their commitment to the witch and the mausoleum.

After slaying their animals, they give the meat to the managers of the mausoleum and the beggars. Dancing on a specific rhythm is part of the exorcism therapy the witches are practicing inside of the mausoleums. During the enchanted dance, people have to wear particular colors connected with the demon 
possessing them. The red color is a predominant color in these wicked therapies. While dancing, they do unbelievable stuff such as drinking hot water, hitting themselves with knives, laying on needles, and even eating glass. People involved in this particular witch dance report that they do not feel any pain because their demons are helping them.

\section{The Mausoleum of "Moulay Abdellah Ben Hussain" in Tamesloht Village: A Case Study}

\subsection{A Biographical Note}

Moulay Abdellah Ben Hussain [3] is a Moroccan Muslim scholar who lived in the fourteenth Century in Tamesloht, a village not far from Marrakesh. His community built a mausoleum on his tomb after his death because he was a good man and a scholar in his lifetime. He came from a noble family well-known for its spirituality.

\subsection{Ceremonies and Rituals}

The rituals and activities that Moroccans practice while visiting the tomb of Moulay Abdellah Ben Hussain in Tamesloht village are surprising. The seasonal festivity includes different activities and practices. People come with the camel they are offering as a sacrifice to the saint followed by horsemen, inhabitants of the village, and visitors while singing and mourning their saint's death. They continue their march until they encompass the tomb and start a mysterious reception which is a mixture of celebration and grief, laughter and lamentations and never stopping their alienated dance. This ceremony lasts for hours. Then, they head for the butchery and massacre the camel as a sacrifice and a tribute to the saint. They put blood on their foreheads and continue their rituals for the whole day. The next step is the disposal of the meat and the money, brought by tribes, to the descendants of the buried saint. The reason behind slaying a camel is to be grateful for the blessings of the saint and to offer him blood to help them achieve their goals. Thousands of Moroccan visitors scatter for various destinations following their intentions and the specific mausoleum they intend to visit. People expect the saint of the mausoleum to grant them their wishes and all their desires.

Currently, Moroccans visit mausoleums for different purposes. First, as a spiritual duty, a place of worship, second a therapeutic site, and a bewitching spot. Some people visit mausoleums to ask forgiveness and mercy from God via the so-called saint. Others attend mausoleums hoping the saint to discharge their current issues such as sterility, epilepsy, demon possession, insanity, joblessness, spinsterhood, and lack of success and so many other issues. The mausoleums in Morocco are related to miserable and lost souls and thought to give divine and spiritual comfort to those lost humans. The most striking element is the believed possessed people during their exorcism session. Each of the visitors hangs a lock on one of the mausoleum windows for different motives, and in the hope of get- 
ting their illusions granted. These reasons vary from breaking a spell, buying a house, to other mysterious intentions such as getting married or making men and women fall in love under a spell. Subsequently, they drink some water from the mausoleum's source to head for additional purposes.

\subsection{The Benefits and Drawbacks of Moulay Abdellah Ben Hussain's in Tamesloht Village [4]}

One of the questions given to the inhabitants of this village is about the advantages and drawbacks of having this famous mausoleum in their community. The respondents agree unanimously on the village's thriving economically during the festivities of the mausoleum. Thousands of visitors come every year to the mausoleum and this is an opportunity for the unemployed to make some money through various business activities as the community suffers from a high rate of unemployment. The poverty and lack of economic projects impact the inhabitants of this community.

We asked people of this community about their opinion. Our sample is composed of 100 individuals who are interviewed in the Tamesloht community. The ages of 40 of them range between 12 to 18 years old. Those are the ones who declare that the presence of the saints' tomb in their village has a lot of benefits. While 60 of them whose ages vary between 18 to 60 years old affirm that having this mausoleum in their community is unethical and sinful. They think that one of the most important drawbacks of having the saints' grave in their village is witchcraft and paganism. Ten out of sixty complain about the loud music during the festival, in addition to the left trash when the celebration is finished. The economic prosperity and entertainment during the festivities make the village of Tamesloht very famous throughout the country. 35 inhabitants of Tamesloht out of 40 stated that the economic expansion is an advantage of having this grave in the community. Five reported the enjoyment and entertainment are suitable for the community.

\section{Conclusions}

Finally, the reasons behind visiting mausoleums in Morocco vary from one person to another. Some declare they require blessings and religious duty. For others, they consider mausoleums as alternatives to hospitals. While others claim these are some institutions for entertainment and enjoyment. Also, the sinister ceremonies that hang around or inside the mausoleums are prostitution and sorcery. In addition, paganism is present inside these mausoleums. The most well-known practice of these mausoleums' sorcerers is witchcraft and magic. Consequently, this study reveals the hidden intentions and practices linked to visiting mausoleums in Morocco.

It is interesting to mention, in this respect, that the official religion in Morocco is Islam and that Islam forbids such practices.

"May Allah (God) curse people who have taken the graves of their prophets 
as mosques.” [5]

Finally, Moroccans visit mausoleums for various reasons, to achieve healthy, spiritual, personal purposes or to use satanic black magic to harm others. Some practices are very dangerous and should be banned by authorities. Many reasons drive those people to visit mausoleums, traditions and beliefs, poverty, and entertainment besides magic and adultery are the main purposes of those believers. The visitors practice numerous rituals depending on the visited mausoleum and the desired wish.

\section{Conflicts of Interest}

The author declares no conflicts of interest.

\section{References}

[1] Omar, Y. (2018) 45 Minutes of Sorcery for Profit. youtube/welyJh4Evvg.

[2] https://www.wikiwand.com/fr/Tameslohte (commune)

[3] https://fr.wikipedia.org/wiki/Tameslouht

[4] https://fr.wikipedia.org/wiki/Abdellah ben Hassoun

[5] Ruling on Praying in a Mosque in Which There Is a Grave (2019). https://aliftaa.jo/QuestionEn.aspx?QuestionId=3468\#.YQpNGL0zaUl 